Aksaray University
Journal of Science and Engineering
e-ISSN: 2587-1277
http://dergipark.gov.tr/asujse
http://asujse.aksaray.edu.tr

Research Article

\title{
Antimicrobial and Antioxidant Evaluation of Fruit Extract from Cornus mas $\mathbf{L}$.
}

Demet Yigit*

Department of Science Education, Education Faculty, Erzincan University, Erzincan, Turkey

-Received Date: 20 Jul 2017

-Revised Date: 27 Nov 2017

-Accepted Date: 27 Dec 2017

-Published Online: 07 Jan 2018

\begin{abstract}
In this present study, water and methanol extracts of Cornelian cherry fruits (Cornus mas L.) were studied for evaluating of antioxidant and antimicrobial properties. The antioxidant properties were evaluated by determination of 2,2-Diphenyl-1-picrylhydrazyl (DPPH) radical scavenging ability and lipid peroxidation inhibition activity. Also total phenolic contents of the extracts were detected by Folin method. The extracts of the fruits have antioxidant potential. The DPPH radical scavenging activity was higher in water extract $(36.6 \%)$ than the methanol extract $(30.6 \%)$. Unlike, methanol extract of fruits have more activity (18.9\%) than water extract $(16.7 \%)$, also with higher phenolic compound contents. Antimicrobial activities of above extracts were also tested against 93 clinical isolates of human pathogenic strains belonging to 5 bacteria (Entorobacter aerogenes, Escherichia coli, Proteus mirabilis, Pseudomonas aeroginosa, Staphylococcus aureus) and 5 yeast species (Candida albicans, Candida glabrata, Candida krusei, Candida parapisilosis, Candida tropicalis) by diskdiffusion method. The results showed cornelian cherries are potentially rich source of antimicrobial agents. The most effective antibacterial activity was expressed by methanol and water extract of cornelian cherry fruit against $S$. aureus with $25 \mathrm{~mm}$ inhibition zone and 0.156 $\mathrm{mg} / \mathrm{ml}$ Minimum Inhibitory Concentration (MIC) value. Only methanol extracts of the fruit have antifungal activity against tested human pathogen clinic isolates.
\end{abstract}

\section{Keywords}

Antimicrobial activity, Antioxidant activity, Cornelian cherry

\footnotetext{
*Corresponding Author: Demet Yigit, Tel: +90-446-224-0089; E-mail: demyigit@ hotmail.com
} 


\section{INTRODUCTION}

Fruits and vegetables are healthy and functional foods that associated with a reduced risk of major chronic diseases such as cancer and cardiovascular disease [1]. These properties of fruits and vegetables have been attributed to the various antioxidant compounds [2]. There is a lot of evidence to show that free radicals cause oxidative damage to proteins, lipids and nucleic acids. In present, the natural history or etiology or of a number of diseases including cancer and cardiovascular disease. Free radicals are the most factors responsible from these diseases [3]. Therefore, antioxidants, which can neutralize free radicals, may be having the most importance in the prevention of these diseases [4].

Fruits and vegetables contain many different antioxidant components. Flavones, flavonones, isoflavones, anthocyanins, catechin, and isocatechin are some polyphenols that are frequently components of the human diet demonstrated have strong antioxidant activities [5, 6].

Medicinal plants are the greatest source of a variety of drugs. Especially, the antimicrobial activity of plant extracts has many applications, including pharmaceuticals, natural therapies and alternative medicine [7]. In fact, fruits and vegetables not only a primary food source also they have contain a variety of bioactive components, which might have potential beneficial health effects. Therefore, fruits and vegetables exhibit important potency against human bacterial and fungal pathogens [8].

Cornelian cherry (Cornus mas L.) are widely grown in different region of Turkey. It ranges from a shrub to a small tree which is reaching a height of up 7-8 $\mathrm{m}$, with dark brown branches and greenish twigs. The leaves are opposite, $4-10 \mathrm{~cm}$ long and ovate to oblong. The flowers are 5-10 $\mathrm{mm}$ in diameter with yellow petals and produced in clusters of 10-25 together in the late winter. The fruit is drupe, oblong, red about $2 \mathrm{~cm}$ long and $1.5 \mathrm{~cm}$ in diameter containing a single seed [9].

In Turkey, cornelian cherries are not only used fresh but also consumed for producing jam, fruit marmalade syrup and several types of soft drinks [10]. Cherries are rich source of vitamins and minerals, including potassium, $\alpha$-tocopherol, ascorbic acid, biotin, riboflavin and a great source of fiber and contain a high amount of anthocyanin $[11,12]$. Besides consumption as food, the plant leaves, barks and fruits are used as traditional medicine in Turkey. The plant have been used for asthma attack, coughs, bronchitis, diarrhea, diabetes, hemorrhoids, gastrointestinal disorders, healing wound and as a diuretic, wound healing, anti-inflammatory, urinary antiinflammatory, and enhance immune system [9]. 
Cherries has been still under researched for their fruits are rich in vitamin, organic acid, fatty acid and tannins $[10,13]$ especially in recent years studies have focused on the antioxidant activity of this plant [14]. Although few groups reported the antimicrobial screening of the extracts of C. mas, no specific study on antifungal activity of this plant extract. Dinda and coworkers reported in their review that a systematic study could be useful to develop a new therapeutic drug from C. mas [9].

To the best of our knowledge there has been only one report in the available literature that explaining the antifungal activity of extracts against Candida albicans. The specific objectives of this study were (1) to determine the total phenolic contents, and antioxidant properties of cornelian cherries, (2) to investigate the antimicrobial properties on some human pathogenic clinical isolates, especially different Candida species.

\section{MATERIALS AND METHODS}

\subsection{Preparation of Extracts}

The cornelian cherry (C. mas L.) fruits were collected at their optimum maturity from Bayırbağ region, Erzincan, Turkey. The fresh fruit samples were transported to the laboratory and the seeds were removed manually. The fruits were extracted with methanol in a Soxhlet apparatus for $24 \mathrm{~h}$. Then methanol was evaporated with a rotary evaporator. The water extracts were also prepared by adding boiling water to $20 \mathrm{~g}$ of material in a glass flask and incubated at room temperature for 2 hours on a rotating shaker $(200 \mathrm{rpm})$. The mixture was filtered using Whatman (No.1) filter paper and then the filtrate was lyophilized. All the extracts were stored in freezer at $-24{ }^{\circ} \mathrm{C}$ until use [15].

\subsection{Test Microorganisms}

Antimicrobial activity tests were carried out against clinical isolates of 53 bacterial strains and 40 Candida strains. Microorganisms were provided by Department of Clinical Microbiology, Medicine Faculty, Erzurum. Microorganism species, isolation origins and numbers were given in Table 1.

\subsection{Antimicrobial Activity}

\subsubsection{Disk diffusion assay}

The methanol and water extraction of fruits were dissolved with solvents (methanol and sterile distilled water). Final concentration was adjusted $30 \mathrm{mg} / \mathrm{ml}$. Antimicrobial test were carried out by disc-diffusion method, using suspension containing $10^{8}$ colony forming unit (CFU)/ml of bacteria and $10^{6} \mathrm{CFU} / \mathrm{ml}$ of yeast spread on nutrient agar. The disc $(6 \mathrm{~mm}$ in diameter) were 
impregnated with extracts and placed on the inoculated nutrient agar (NA). Negative controls were prepared using the same solvents (methanol and water). Positive controls were used as Ofloxacin for Gram-positive bacteria, Cefaperazone-sulbactam for Gram-negative bacteria and Amphotericin B for Candida spp. The inoculated plates were incubated at $37^{\circ} \mathrm{C}$ for $24 \mathrm{~h}$ for bacteria and at $35^{\circ} \mathrm{C}$ for $48 \mathrm{~h}$ for yeast. Then antimicrobial activity was evaluated by measuring the inhibition zone [15].

\subsubsection{Minimal inhibition concentration (MIC)}

The minimal inhibition concentration (MIC) values were determined for the microorganisms, which were found to be sensitive in disc-diffusion assay. MIC values of the extracts against microbial strains were determined based on a micro-well dilution method. The inoculations of microorganisms were prepared from $12 \mathrm{~h}$ broth cultures and suspensions were adjusted to 0.5 McFarland standard turbidity. Firstly, the extracts dissolved in $10 \%$ dimethyl sulfoxide were diluted to $10 \mathrm{mg} / \mathrm{ml}$ and then serial two fold dilutions were made in a concentration range $(0.078-10 \mathrm{mg} / \mathrm{ml})$ in a sterile test tube containing nutrient broth. The 96-well plates were prepared by dispensing into each well $95 \mu 1$ nutrient broth (NB) and 51 of the inoculums. A $100 \mu 1$ of extracts initially prepared at the concentration of highest concentration was added the first well, then $100 \mu 1$ from serial dilutions was transferred into other wells. The plates incubated for $24 \mathrm{~h}$ (for bacterial strains) and $48 \mathrm{~h}$ (for fungal strains). The MIC was defined as the lowest concentration of the extracts to inhibit the growth of microorganisms [15].

\subsection{Antioxidant Activity}

The antioxidant activity was determined by the thiocyanate method. Stock solutions of extracts were prepared at $2 \mathrm{mg} / \mathrm{ml}$ concentration. Stock solutions were mixed with $2.5 \mathrm{ml}$ of $0.02 \mathrm{M}$ linoleic acid emulsion [contains an equal weight of Tween-20 (Sigma) in pH 7.4 phosphatebuffered saline], and the final volume was adjusted to $5 \mathrm{ml}$ with phosphate-buffered saline $(0.02$ $\mathrm{M}, \mathrm{pH}$ 7.4) in a test tube and incubated in darkness at $40{ }^{\circ} \mathrm{C}$. Final concentrations of the extracts were $100 \mu \mathrm{g} / \mathrm{ml}$. Butylated hydroxytoluene (BHT) was used as positive control (100 $\mu \mathrm{g} / \mathrm{ml})$. The amount of peroxide was determined by measuring the absorbance at $500 \mathrm{~nm}$ after coloring with $\mathrm{FeCl}_{2}$ and thiocyanate after $24 \mathrm{~h}$ incubation. Lower absorbance indicated higher antioxidant activity. Measurements of antioxidant activity were carried out for three sample replications, and the values are the average of three replicates. This activity was given as percent Lipid Peroxidation Inhibition and calculated with the equation

Lipid peroxidation inhibition $(\%)=\left[\frac{\text { ControlAbs }- \text { SampleAbs }}{\text { ControlAbs }}\right] \times 100$ 


\subsection{DPPH Radical-Scavenging Activity}

At first, $0.5 \mathrm{mM}$ DPPH radical solution in methanol was prepared, and then $1 \mathrm{ml}$ of this solution was mixed with $3 \mathrm{ml}$ of the sample solution. Final concentrations of extracts were $100 \mu \mathrm{g} / \mathrm{ml}$. BHT was used as a positive control at the same concentration. After incubation for $30 \mathrm{~min}$ in the dark, the absorbance was measured at $517 \mathrm{~nm}$. Decreasing the absorbance of the DPPH solution indicates an increase in DPPH radical scavenging activity. This activity was given as percent DPPH radical scavenging, and calculated with the equation

Activity\% $=\left[\frac{\text { ControlAbs }- \text { SampleAbs }}{\text { ControlAbs }}\right] \times 100$

Control solution contained $1 \mathrm{ml}$ of DPPH solution mixed with $3 \mathrm{ml}$ of ethanol. The measurements of DPPH radical scavenging activity were carried out for three sample replications, and the values are an average of three replicates [15].

\subsection{Determination of Total Phenolic Compounds}

Extract solution was transferred into a tube and then final volume was adjusted to $4 \mathrm{ml}$ by addition of distilled water. Afterward, $0.25 \mathrm{ml}$ of Folin-Ciocalteu Reactive was added into this mixture and after $3 \mathrm{~min} 0.75 \mathrm{ml}$ of $\mathrm{Na}_{2} \mathrm{CO}_{3}$ solution was added. Mixture was shaken on a shaker for $2 \mathrm{~h}$ at room temperature and then absorbance was measured at $760 \mathrm{~nm}$. Amount of total phenolic compounds was carried out for three sample replications, and the values are an average of three replicates. Gallic acid was used as the standard for a calibration curve. The phenolic compound content was expressed as gallic acid equivalent using the following equation based on the calibration curve:

$\mathrm{Y}=0.2582 \mathrm{X}$

Where $\mathrm{Y}$ is the absorbance of the sample and $\mathrm{X}$ is the gallic acid the equivalent $(\mu \mathrm{g} / \mathrm{ml})$ [15].

\section{RESULTS AND DISCUSSION}

\subsection{Antioxidant Activities}

The antioxidant activities of water and methanol extracts of Cornelian cherry fruits were determined using the thiocyanate method in which the amount of peroxides formed in linoleic acid emulsion during incubation is determined spectrophotometrically.

Although there was no too much difference between the antioxidant activities of water and methanol extracts, the high antioxidant activity was obtained from methanol extract, whereas the low activity was obtained from water extract cornelian cherry fruits $(16.7 \%$ and $18.9 \%$, respectively) (Figure 1). 
The Cornelian cherry fruits are a rich source of high phenolic content, ascorbic acid and anthocyanin content, which are also responsible for color and taste and also their antioxidant properties $[10,16-18]$. It was observed that all the extracts had antioxidant potential, and our findings were in agreement with these data.

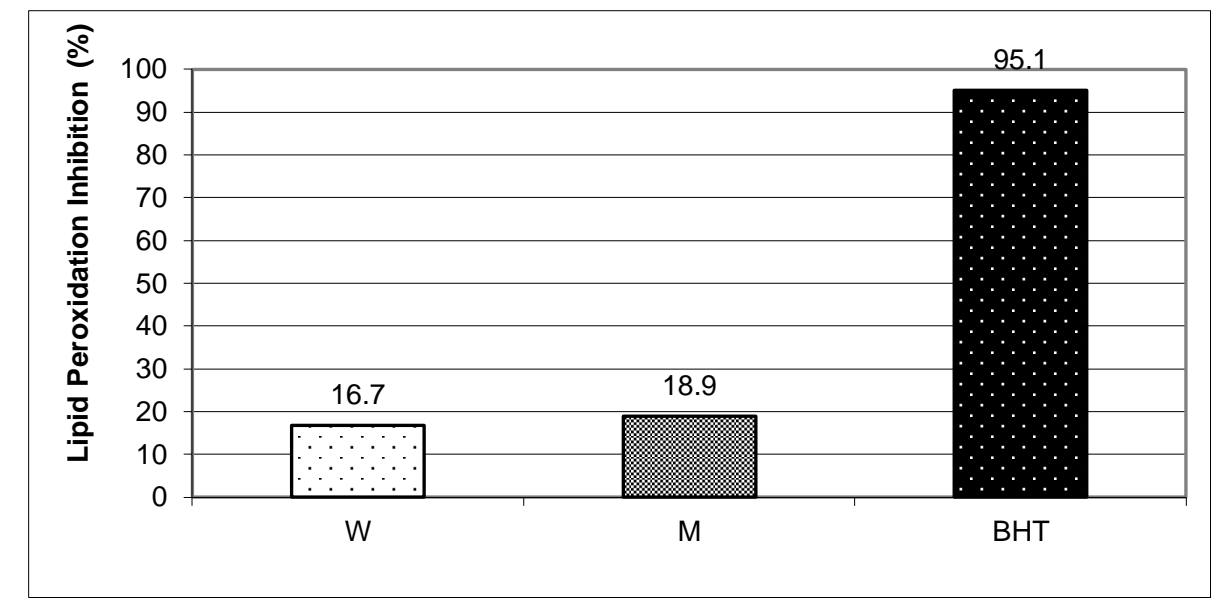

Figure 1. The Inhibition of Lipid Peroxidation by $100 \mu \mathrm{g} / \mathrm{ml}$ extract and BHT. (M: Methanol extract, W: Water extract; BHT: Butylated hydroxytoluene)

The DPPH free radical has been used widely for determination of primary antioxidant activity, that is, the free radical scavenging activities of pure antioxidant compounds, plant and fruit extracts and food materials. The assay is based on the reduction of DPPH radicals in methanol and water, which causes an absorbance drop at $517 \mathrm{~nm}$.

At the concentration of $100 \mu \mathrm{g} / \mathrm{ml}$ water and methanol extract of cornelian cherry fruit, the scavenging activities were $36.6 \%$ and $30.6 \%$, respectively (Figure 2). It is interesting to find that although the methanol extracts had the higher antioxidant activity; their DPPH radical scavenging activities were lower than the water extracts. However, when compared to the rates of DPPH activity of common synthetic antioxidants used in foods and fruit extracts, the DPPH radical scavenging activity of water and methanol extracts of cornelian cherry was lower than BHT (Fig. 2). The Cornelian cherry fruit juice was found to have strong antioxidant power, higher than that of other fruit juices [19]. Also, some authors were reported potential antioxidant activity of Cornelian cherry leaves and flowers [20, 21].

The total phenolic compounds present in the extracts were determined using the Folin-ciocalteu phenol reagent. Like Lipid Peroxidation activity, the amounts of total phenolic compounds were higher in the methanol fruit extracts than in the water extracts. The phenolic compounds content was present as $4.5 \mu \mathrm{g} / \mathrm{ml}$ gallic acid equivalent in $100 \mu \mathrm{g} / \mathrm{ml}$ methanol extract of cornelian cherry fruits, and the content was obtained from $100 \mu \mathrm{g} / \mathrm{ml}$ water extract with $1.7 \mu \mathrm{g} / \mathrm{ml}$ gallic acid equivalent (Table 1). 
Yigit, D. (2018). Aksaray University Journal of Science and Engineering, 2(1), 41-51.

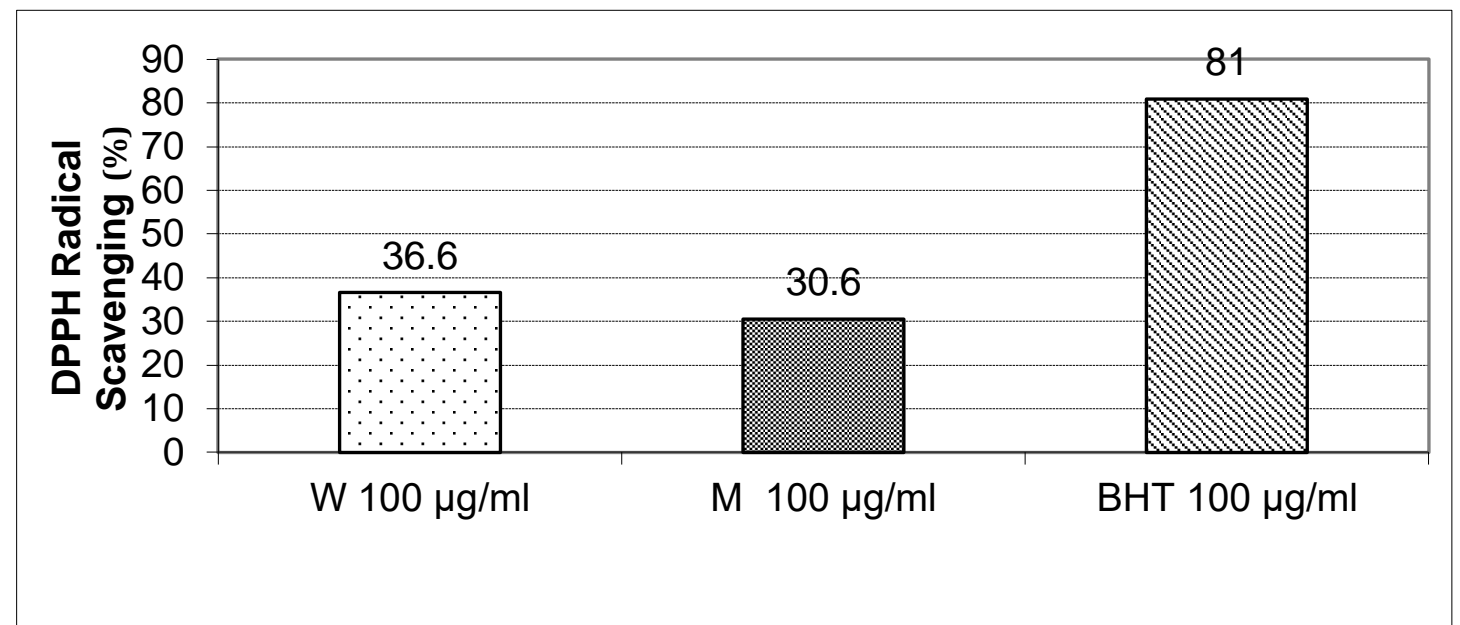

Figure 2. DPPH Radical Scavenging Activity, (M: Methanol extract, W: Water extract; BHT: Butylated hydroxytoluene)

Table 1. Total phenolic content of Cornelian cherry fruits

\begin{tabular}{lc}
\hline Fruit Extract & Gallic acid equivalent $(\boldsymbol{\mu g} / \mathbf{m L})$. \\
\hline Water & 1.7 \\
Methanol & 4.5 \\
\hline
\end{tabular}

Generally, the extracts that contain a high amount of phenolic compounds also exhibit high antioxidant activity [22]. Gil and coworkers reported that there was a strong correlation $(\mathrm{r}=0.930-0.960)$ between total phenolic and antioxidant activity in some stone fruits [23]. This might be due to synergism among the antioxidants in the mixture. The cornelian fruits are rich in anthocyanins and phenolic contents with an average of 223-292 mg cyanidin 3-O-glucoside equivalents (CGE) and 281-704 mg Gallic acid equivalents (GAE) per $100 \mathrm{~g}$ of fresh fruits, respectively [17, 24]. Not only the fruits but also the leaves are rich in phenolic content $(11.73 \%)$ compared to fruits $(9.11 \%)$ [25].

\subsection{Antimicrobial Activities}

The antimicrobial activity of water and methanol extracts of cornelian cherry fruits evaluated by the disk-diffusion method. Totally 93 clinic isolates of human pathogenic microorganism belonging to 5 bacteria and 5 Candida spp. were used in these investigations (Table 2). The negative controls showed no inhibiting effect. The inhibition diameters and MIC values of positive controls were ranging to $18-20 \mathrm{~mm} ; 0.12-1 \mu \mathrm{g} / \mathrm{mL}$ for Ofloxacin, $19-22 \mathrm{~mm}$; $0.5-1$ $\mu \mathrm{g} / \mathrm{mL}$ for Cefaperazone and $12-15 \mathrm{~mm} ; 0.12-0.5 \mu \mathrm{g} / \mathrm{mL}$ for Amphotericin B, respectively.

Our findings showed that the methanol and water extracts of fruits had antibacterial activity against Gram-positive and Gram-negative bacteria. The fruit extract proved to be active against 3 of the 5 bacteria species of human pathogenic clinic isolates. The highest antibacterial activity was expressed by methanol extract of cornelian cherry fruits against $S$. aureus with $25 \mathrm{~mm}$ 
inhibition zone and $0.156 \mathrm{mg} / \mathrm{ml} \mathrm{MIC} \mathrm{value} \mathrm{(Table} \mathrm{3).} \mathrm{Against} \mathrm{E.} \mathrm{coli} \mathrm{and} \mathrm{P.} \mathrm{aueroginosa,} 10$ $\mathrm{mm}$ inhibition zone diameter and $0.312 \mathrm{mg} / \mathrm{ml}$ MIC values were found, respectively. $E$. aerogenes and $P$. mirabilis were not inhibited.

Table 2. Isolation origins and numbers of bacteria and Candida species

\begin{tabular}{lccccccc}
\hline Microorganisms & Urine & Blood & Wound & Ear & Throat & Mouth & Total \\
\hline E. aerogenes & 8 & - & 2 & - & - & - & 10 \\
E. coli & 9 & 1 & 1 & 1 & - & - & 12 \\
P. miribalis & 7 & 1 & 1 & 1 & - & - & 10 \\
P. aeroginosa & 2 & 1 & 5 & - & - & - & 8 \\
S. aureus & 2 & 7 & 2 & 1 & 1 & - & 13 \\
C. albicans & 2 & 8 & 1 & - & 1 & 1 & 13 \\
C. glabrata & 5 & - & - & - & 2 & - & 8 \\
C. krusei & - & 1 & 2 & - & 1 & - & 4 \\
C. parapisilosis & 1 & 5 & - & - & - & 2 & 8 \\
C. tropicalis & 1 & 4 & 1 & - & - & 1 & 7 \\
TOTAL & & & & & & & 93
\end{tabular}

Table 3. Antimicrobial activity of methanol and water extracts of Cornelian cherry fruits against some clinic isolates.

\begin{tabular}{|c|c|c|}
\hline \multirow[b]{2}{*}{ Microorganisim } & Methanol Extracts & Water Extracts \\
\hline & \multicolumn{2}{|c|}{ Inhibition Zone Diameter (mm)/MIC $\mathrm{mg} / \mathrm{mL}$. } \\
\hline E. aerogenes & - & - \\
\hline E. coli & $10 \pm 1.6 /(0.312)$ & $10 \pm 1.3 /(0.312)$ \\
\hline P.miribalis & _ & _ \\
\hline P. aeroginosa & $10 \pm 1.2 /(0.312)$ & _ \\
\hline S. aureus & $25 \pm 0.6 /(0.156)$ & $25 \pm 1.8 /(0.156)$ \\
\hline C. albicans & $8 \pm 0.3 /(0.625)$ & _ \\
\hline C. glabrata & _ & - \\
\hline C. krusei & _ & _ \\
\hline C. parapisilosis & _ & _ \\
\hline C.tropicalis & _ & _ \\
\hline
\end{tabular}

_. Not active, inhibition zone was no greater than $6 \mathrm{~mm}$; (7-12 mm), moderately active; (> 12), highly active

For screening antifungal activity of cornelian cherries, there was only one activity detected. Anticandidal activity was exhibited by methanol extract of fruits against Candida albicans with $8 \mathrm{~mm}$ inhibition zone and $0.625 \mathrm{mg} / \mathrm{mL}$ MIC value. The fruit extracts exhibited no activity against 4 human pathogenic Candida spp. According to the results obtained in the course of current study, the Candidal strains were found to be resistant to both fruit extracts screened. Similarly, it has been previously reported that fungi are most resistant to plant extracts than bacteria [26]. 
Antimicrobial activity of leaf extracts of European cornel has been reported [27]. Hexane extract of Cornelian cherry seeds $(10 \mathrm{mg} / \mu \mathrm{L})$ showed significant antibacterial activity against S. aureus and E. coli [28]. On the other hand different authors [29] reported methanol and ethanol extracts of fruits, leaves and seeds of Cornelian cherry showed significant antibacterial activity against $S$. aureus, E. coli and $P$. aeruginosa and antifungal activity against $C$. albicans and A.fumigates. Also, Kyriakopoulos and Dinda mentioned fruit extract was exhibited strong antibacterial activity against $S$. aureus [30]. Our results are in agreement with these reports above that we also detected significant activity against $S$. aureus and moderate activity against E. coli, P. aeruginosa and Candida albicans.

\section{CONCLUSIONS}

In conclusion, our findings on antibacterial activity of fruit extracts could justify some ethnopharmacological uses against diarrhea and gastrointestinal disorders because we detected activities of these fruits against some human pathogens (E. coli). On the other hand, the antioxidant activity could support the ethnopharmacological uses such as improving immune function. In addition, these results represent that these fruits are not only as a rich source of food but also as a valuable importance with high antioxidant and antimicrobial effects in ethnobotanical fields.

\section{REFERENCES}

[1] P.C.H. Hollman, Evidence of health benefits of plant phenols: local or systemic effects. J. Sci. Food Agric. 81 (2001) 842-852.

[2] D. Steinberg, Antioxidants and atlerosclerosis: Accurent assessment. Circulation 84 (1991) 14201425.

[3] K. Shindo, M. Kimura, M. Iga, Potent antioxidative activity of cacalol, a sesquiterpene contained in Cacalia delphiniifolia Sleb et Zucc. Biosci. Biotech. Biochem. 8 (2004) 1393-1394.

[4] K. Saha, N.H. Lajis, D.H Israf, A.S. Hamzah, S. Khozirah, S. Khamis, A. Syahida, Evaluation of antioxidant and nitric oxide inhibitory activities of selected Malaysian medicinal plants. J. Ethnophar. 92 (2004) 263-267.

[5] L. Bravo, Polyphenols: Chemistry, dietary sources, metabolism, and nutritional significance. Nutr. Rew. 56 (1998) 317-333.

[6] P.M. Kris-etherton, K.D. Hecker, A. Bonamone, S.M. Coval, A.E. Binkosk, K.F. Hilgert, A.E. Griel, T.D. Etherton, Bioactive compounds in foods: their role in the prevention of cardiovascular disease and cancer. Am. J. Med. 113 (2002) 718-818.

[7] M. Lis-balchin, S.G. Deans, Bioactivity of selected plant essential oil against Listeria monocytogenes. J of App. Bacteriology 82 (1997) 759-762.

[8] P. Cos, A.J. Vlietinck, D. Vander, L. Maes, Anti-infective potential of natural products? How to develop a stronger in vitro proof-of concept. J. Ethnophar. 106 (2006) 290-302.

[9] B. Dindaa, A.M. Kyriakopoulosb, S. Dindac, V. Zoumpourlisd, N.S.Thomaidise, A. Velegrakif, C. Markopoulosg, M. Dindah, Cornus mas L. (cornelian cherry), an important European and 
Asiantraditional food and medicine: Ethnomedicine, phytochemistry and pharmacology for its commercial utilization in drug industry. J. Ethnophar. 193 (2016) 670-690.

[10] F. Demir, İ.H. Kalyoncu, Some nutritional, pomological and physical properties of cornelian cherry. J Food Eng. 60 (2003) 335-341.

[11] G.E. Pantelidis, M. Vasilakakis, G.A. Manganaris, G.R, Diamantidis, Antioxidant capacity, phenol, anthocyanin and ascorbic acid contents in raspberries, blackberries, red currants, gooseberries and cornelian cherries. Food Chem. 102 (2006) 777-783.

[12] J. Dexian, L. Xing, Y. Jianjun, Z.J.J. Zhang, C. Zhangfu, Review on the research progress in the chemistry and pharmacology of Asiatic Cornelian Cherry Fruit. Chinese J. Intern. Med. 9 (2002) 83-85.

[13] E.V. Krivoruchko, Carboxylic acids from Cornus mas. Chem. Nat. Compd. 50 (2014) 112-113.

[14] B. Moldovan, A. Filip, S. Clichici, R. Suharoschi, P. Bolfa, L. David, Antioxidant activity of Cornelian cherry (Cornus mas L.) fruits extract and the in vivo evaluation of its anti-inflammatory effects. J. Func. Foods 26 (2016) 77-87.

[15] D. Yiğit, N. Yiğit, A. Sülün, Screening of antioxidant and antimicrobial potential of hawthorn (Creatagus monogyna) fruit and leaves extracts. EÜFBED 7(2) (2014) 162-171.

[16] D. Kim, H.J. Heo, Y.J. Kim, H.S. Yang, C.Y. Lee, Sweet and sour cherry phenolics and their protective effects on neuronal cells. J. Agric. Food Chem. 53 (2005) 9921-9927.

[17] S. Tural, I. Koca, Physicochemical and antioxidant properties of cornelian cherry fruits (Cornus mas L.) grown in Turkey. Sci. Hortic. 116 (2008) 362-366.

[18] H. Hamid, H. Yousef, H. Jafar, A. Mohammad, Antioxidant capacity and phytochemical properties of cornelian cherry (Cornus mas L.) genotypes in Iran Scientia Hort. 129 (2011) 459-463.

[19] M. Gastol, M., Krosniak, M. Derwisz, J. Dobrowolska-Iwanek, Cornelian cherry (Cornus mas L.) juice as a potential source of biological compounds. J. Med. Food 16 (2013) 728-732.

[20] A.Serteser, M. Kargığlu, V. Gök, Y. Bağc1, M. Özcan, D. Arslan, Antioxidant properties of some plants growing wild in Turkey. Grasas Y Aceites 60 (2009) 147-154.

[21] M.S. Stankovic, M. Zia-Ul-Haq, B.M. Bojovic, M.D. Topuzovic, Total phenolic, flavonoid content and antioxidant power of leaf, flower and fruits from cornelian cherry. Bulg. J. Agric. Sci. 20 (2014). 358-363.

[22] S.P. Wong, L.P. Leong, J.H.W. Koh, Antioxidant activities of aqueous extracts of selected plants. Food Chem. 99 (2006) 775-783.

[23] M.I. Gil, F.A. Tomas-Barberanhess, B. Pierce, A.A. Kader, Antioxidant capacities, phenolic compounds, carotenoids, and vitamin $C$ contents of nectarine, peach, and plum cultivars from California. J Agric. Food Chem. 50 (2002) 4976-4982.

[24] B.M. Popovic, D. Stajner, K. Slavko, B. Sandra, Antioxidant capacity of cornelian cherry (Cornus mas L.)-comparison between permanganate reducing antioxidant capacity and other antioxidant methods. Food Chem. 134 (2012) 734-741.

[25] A.S. Milenkovic-Andjelkovic, M.Z. Andjelkovic, A.N. Radovanovic, B. Radovanovic, V Nikolic, Phenol composition, DPPH radical scavenging and antimicrobial activity of Cornelian cherry (Cornus mas) fruit and leaf extracts. Hem. Ind. 69 (2015) 331-337.

[26] M.C. T. Duarte, G.M. Figueria, A. Sartoratto, V.L.G. Rehder, C. Delarmelina, Anti-Candida activity of Brazilian medicinal plants. J. Ethnophar. 97 (2005) 305-311.

[27] A.S. Milenkovic-Andjelkovic, M.Z Andjelkovic, A.N. Radovanovic, B.C. Radovanovic, V. Randjelovic, Phenol composition, radical scavenging activity and antimicrobial activity of berry leaf extracts. Bulgarian Chem. Commun. V 48 (1) (2016) 27-32. 
[28] N. Mamedov, L.E. Craker, Cornelian cherry. A prospective source for phytomedicine. Acta Hortic. 629 (2004) 83-86.

[29] P. Krzysciak, M. Krosniak, M. Gastol, D. Ochonska, W. Krzysciak, Antimicrobial activity of Cornelian cherry (Cornus mas L.). Post. Fitoter. 4 (2011) 227-231.

[30] A.M. Kyriakopoulos, İ. Dinda, Cornus mas (Linnaeus) Novel Devised Medicinal Preparations: Bactericidal Effect against Staphylococcus aureus and Pseudomonas aeruginosa. Molecules 20 (2015) 11202-11218. 